\title{
БЕСКОРНЕВЫЕ ЭНЕРГОГЕНЕРИРУЮЩИЕ ОЧАГИ НЕРАДИОАКТИВНОЙ ПРИРОДЫ В ЛИТОСФЕРЕ (ТЕКТОНО-КЕССОННЫЙ ЭФФЕКТ И ЕГО ВОЗМОЖНАЯ РОЛЬ В СИНТЕЗЕ УГЛЕВОДОРОДОВ)
}

\section{Горяинов П.М.}

Геологический институт КНЦ РАН

Для объяснения энергетической составляющей минералообразующих реакций обычно привлекаются различные глубинные источники (глубинное тепло, энергия активной тектонической динамики и, конечно же, распад радионуклидов). Однако многие, если не подавляющая часть процессов глубокой вещественной дифференциации может быть связана с бескорневыми источниками энергии нерадиоактивной природы. Публикация содержит материалы и размышления на эту тему, которая раскрывает сущность одного из важнейших литосферных явлений - тектоно-кессонного эффекта [1].

\section{Введение}

Проблема образования «нестандартных» минеральных ассоциаций, в особенности сильно восстановленных, сейчас на пике геохимических исследований. В последнее время теория восстановления in situ (как точка зрения, противоположная теории «исходно восстановленного мантийного источника») подкрепляется экспериментами, и главным из альтернативных модификаторов признаются как раз-таки разряды высоких энергий [13]. Процессы, сопровождающие выведение к поверхности нерелаксированных пород, в частности, возникновение в связи с этим градиентов напряжений и избыточных электрохимических связей в твердотельном субстрате, объединены под названием «тектоно-кессонный эффект» (ТКЭ), - по отдаленной аналогии с известным биофизическим явлением $[1,2]$. В зависимости от величины градиента в очагах проявления ТКЭ возникают эмиссионные энергетические потоки различной природы (от акустической, молекулярной, электронной до плазменно-нейтронной). При незначительных градиентах происходит шелушение и лавинное накопление детритуса. При значительном градиенте может происходить частичное плавление с образованием пород смешанного состава (детритус с расплавным и гидрохимическим или более сложным цементом), образование брекчий нескольких поколений, не связанных с воздействием внешних тектонических факторов [10].

\section{Тектоно-кессонный эффект: физические следствия}

Избыточность связей (ионных, ковалентных, металлических) провоцирует энергетическую эмиссию в очаге разгрузки. С этим геодинамическим процессом связано появление плазмоидов и шаровых молний, а также значительные вариации магнитного поля во время землетрясений $[3,4]$. Если кристаллическое вещество (горная порода) находилась в субсолидусном состоянии, то каждое достижение критического состояния (т.е. определенного градиента избыточного напряжения) могло сопровождаться локальными, бескорневыми выплавками. Примеры подобных явлений можно найти в самых разных геологических ситуациях, прежде всего, характеризующихся повышенной энергонасыщенностью. Это явление детально рассмотрено в ряде публикаций $[1,2,8]$.

При моделировании природных реакций глубинного минералообразования, в том числе реакции органического синтеза, обычно учитывают лишь два параметра энергетической «накачки» системы - температуру и давление как факторы, способствующие возрастанию химической активности ионов. Ионизирующее излучение в построении этих моделей обычно не участвует, хотя оно является одним из наиболее эффективных способов введения энергии в систему. Одними из первых на это обратили внимание А.А. Воробьев $[3,4]$ и И.Ф. Вовк $[5,6]$. Возрастание градиентов механического потенциала, как отмечает А.А. Воробьев [4], вызывает не только механическую неустойчивость, но и «механоэлектрические преобразования и возникновение электрических полей, токов, электрических разрядов, а в плазме - плазмохимических, ядерных и термоядерных реакций, теплового и взрывного действия разрядной плазмы». Вот какую природу могут иметь шаровые молнии (плазмоиды), сопровождающие разрядку избыточных тектонических напряжений в литосферных структурах разного масштаба, прежде всего, землетрясения. 


\section{Тектоно-кессонный эффект: химические следствия}

Ионизирующее воздействие на водно-минеральные системы традиционно связывают исключительно с естественной радиоактивностью горных пород [6]. На самом деле «привязка» этих реакций к ионизирующему излучению именно этой природы далеко не очевидна. Так, минералообразующие реакции, обусловленные глубокой диссоциацией воды по невыясненной причине, распространены значительно шире, чем процессы радиоактивного распада. Разрушение кристаллического вещества, разрыв избыточных кристаллических связей порождает не только тепловую эмиссию. По мнению А.А. Воробьева [3], в тектонических процессах энергетические эффекты электрической природы (характер излучения не привязывается к определенной длине волны) превышают все другие ее виды на несколько порядков. Эти процессы, и в общем случае, - тип динамической эволюции связан с проявлением тектоно-кессонного эффекта (рис. 1).

Особая роль в химических изменениях, вызванных ионизирующим излучением в литосфере, принадлежит воде. Вода выступает в подобных условиях и как среда, и как активный участник, источник окислителя или восстановителя, и, наконец, как мощный агент мобилизации, переноса и
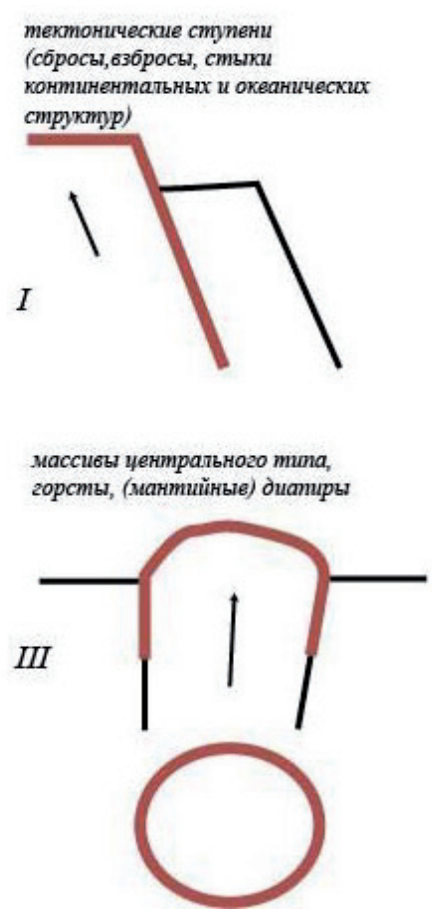

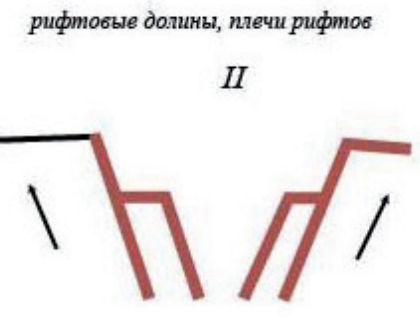

фронтальные части тектоническах чеиуй, островодужсные системы

IV

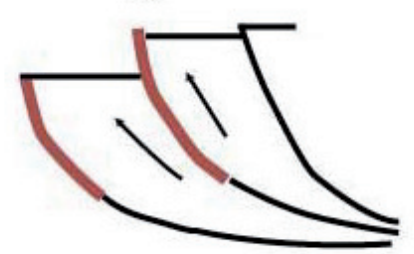

Рис. 1. Схема типовых геодинамических обстановок проявления тектоно-кессонного эффекта.

Красными линиями обозначены зоны локализации наивысших градиентов избыточных давлений и размещения продуктов тектоно-кессонной динамики (включая месторождения металлов, углеводородов) [1].

Примеры месторождений углеводородов, локализованных в ситуациях I-IV: I-шельфовые месторождения мира Калифорния, Карский и Баренцевоморский шельф, II-красноморский и аравийские рифты, III-нефтегазовые и соляные купола, Западно-Сибирские месторождения, IV-Прадхо-Бей (Аляска), Сев. Сахалин.

преобразования вещества и энергии. Ионизирующее облучение воды вызывает высвобождение в ней электронов, атомарного водорода, а также гидроксильных радикалов, т.е. наиболее реакционноспособных и известных в природе частиц. Они в ничтожно короткое время освобождают кристаллическое вещество от избыточной энергии, не рассеивая ее в виде тепла, как это имеет место в безводных средах, - заметим, чрезвычайно редких, - а вступая в химическое взаимодействие с различными контактирующими с флюидом компонентами.

Взаимодействие ионизирующих излучений с водой условно разделяют на несколько стадий: физическую, физико-химическую и химическую [11]. В физическую стадию, общая продолжительность которой составляет $<10^{-13} \mathrm{c}$, происходит передача воде энергии излучения (за время до $10^{-10} \mathrm{c}$ ), а затем идут быстрые процессы молекулярной диссоциации и ионизации. В результате этого об- 
разуются возбужденные молекулы воды $\left(\mathrm{H}_{2} \mathrm{O}^{*}\right)$, положительные ионы (главным образом $\mathrm{H}_{2} \mathrm{O}+$ ) и электроны. В физико-химическую стадию длительностью около $10^{-13}-10^{-10}$ с в системе протекают процессы диэлектрической релаксации в воде, и устанавливается тепловое равновесие. При этом возникают гидратированные электроны $\mathrm{e}_{a q}^{-}$, атомы водорода Н и радикалы ОН. И, наконец, в третью стадию - химическую - $\left(10^{-9}-10^{-8} \mathrm{c}\right)$ протекают различные химические реакции. В чистой воде в эту стадию радикалы рекомбинируют с образованием молекулярных продуктов разложения воды: $\mathrm{H}_{2}$ и $\mathrm{H}_{2} \mathrm{O}_{2}$, а также радикала $\mathrm{HO}_{2}$. Электроны, заторможенные до энергий, недостаточных для ионизации молекул воды, возбуждают их $\left(\mathrm{H}_{2} \mathrm{O} \rightarrow \mathrm{H}_{2} 0^{*}\right)$. Благодаря наличию заряда, замедленный до тепловых скоростей электрон в состоянии поляризовать воду и гидратироваться $\left(\mathrm{e}^{-} \rightarrow \mathrm{e}_{\text {aq }}^{-}\right)$, а затем и образовать атом водорода.

\section{Тектоно-кессонный эффект: геологические следствия}

Иными словами, в облучаемой системе «вода-порода» становятся возможными многие химические реакции, не идущие при нормальных Т и Р в нейтральной среде. К ним относятся, например, окисление не только сульфидов, но и весьма устойчивых алюмосиликатов, и многие другие реакции разложения одних и синтеза других минеральных форм. Понятно, что принятая теория и практика «восстановления» условий минералообразования будет считать их высокотемпературными и высокобарическими, а в случае разложения силикатов на гидратированные и окисленные фазы их начинают связывать с инсоляционными процессами (например, с корами выветривания). На чем построена и систематика метаморфических пород, и моделирование геодинамических режимов их возникновения, и реконструкция палеогеографии ландшафтов.

Вот некоторые эффекты ионизационного воздействие на систему «вода-порода» [6]:

1. Под действием ионизирующего излучения на водонасыщенные горные породы содержащиеся в них элементы с переменной валентностью (железо, хром, марганец, ванадий, уран, молибден, титан и другие) в зависимости от наличия в составе породы акцепторов радикалов того или иного типа (например, органического вещества, сульфидов или кислорода) окисляются или восстанавливаются. Это определяет и состав метаморфических минералов с переменной железистостью, т.е. минералов-индикаторов «синтетических» палеотермометров и палеобарометров. При воздействии ионизирующего излучения органическое вещество (углеродистые соединения) - наиболее чувствительный компонент системы «вода-порода»- легко гидролизуется или, в меньшей степени, взаимодействует с атомарным водородом. Эти два продукта (гидроксил-ион и водород), попадая в скопления рассеянного органического вещества, вызывают окисление и гидрогенизацию, карбоксилирование и декарбоксилирование, окислительную деструкцию и полимеризацию;

2. В результате этого в системе «вода-порода» имеет место ионизационное газообразование (накопление водорода, углекислого и угарного газа, метана) и образование более тяжелых углеводородов, в том числе и ароматических соединений нефтяного ряда. Нерастворимый в воде органический остаток (кероген) постепенно теряет гидроксильные, карбонильные и аминные группы, обогащаясь углеродом в том числе и свободным, вплоть до графита или даже алмаза [6] даже в приповерхностных условиях (!). В пользу химического действия ионизирующих излучений свидетельствует и обнаружение в углистом веществе метаморфических пород графита, алмаза и муассонита в контакте с минералами урана. Весьма интересны материалы Г.Г. Пименова с коллегами [7], указывающие на факт появления в водных резервуарах законтурного обводнения реакторов рентгенографически определяемых фаз графита и даже алмаза. Хотя температура в этих резервуарах не может превышать 60-80 ․ Порой это представляет собой серьезную проблему из-за повышенной электропроводности графитовой пленки на дне этих емкостей. Природа такого графита связана с восстановлением до $\mathrm{C}_{\text {своб }}$ остатков смазки на стенках реактора под воздействием водорода диссоциированой воды.

«Привязка» этих реакций к ионизирующему излучению исключительно радиоактивной природы задержала развитие этой блестящей идеи И.Ф. Вовка [6], ибо оказалось, что универсальность такого источника излучения весьма неочевидна. Так, минералообразующие реакции, обусловленные глубокой диссоциацией воды «невыясненной» природы, распространены значительно шире, чем процессы радиоактивного распада. Источник же ионизирующего излучения нерадиоактивной природы в литосферных процессах весьма распространен. Разрушение кристаллического вещества, 
разрыв избыточных кристаллических связей, т.е. появление свободных кристаллических зарядов, порождает не только тепловую эмиссию. По мнению А.А. Воробьева [3], в тектонических процессах энергетические эффекты электрической природы превышают все другие ее виды на несколько порядков. Эти эффекты и провоцируются тектоно-кессоннм эффектом.

Процессы гидролиза соединений углерода и появление ароматических углеводородов или

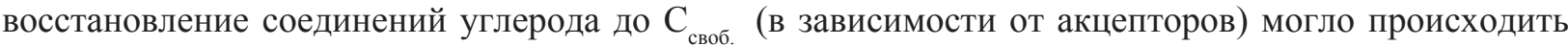
на месте локальной энергетической аномалии, привязанной к нескольким типичным геодинамическим ситуациям (см. рис.). С этой точки зрения возрастная привязка месторождений углеводородов к вмещающим породам скорее всего, ошибочна, так как возраст субстрата и углеводородов могут не совпадать. На это указывает и появление скоплений углеводородов в докембрийских ультраметаморфитах и даже гранитах [12]. С этой же точки зрения современное нефтеобразование кажется вполне реальным в разных породных системах. Более того, вскрытие природных углеводородных «емкостей» создает предпосылки для появления нового углеводородного вещества в литосфере за счет искусственного создания градиентов избыточных напряжений и инициирования новых очагов эмиссионных потоков, новых проявлений тектоно-кессонного эффекта.

К месту заметим, что и образование гремучей смеси (водорода и кислорода) в процессе диссоциации воды предположительно и есть истинная причина многих катастрофических взрывов и выбросов в подземных горных выработках, которую не всегда справедливо относят к нарушениям техники безопасности. Горные инженеры, не сомневаясь, связывают ее со спонтанным поступлением и взрывом метана. Это заключение особенно актуально, к примеру, для выработок, никогда не относившихся к числу метаноопасных. А послевзрывные следы окисей углерода (органического или даже свободного) указывают, скорее, на горение деревянных или пластмассовых конструкций, чем на присутствие неучтенного метана.

Можно ли видеть в идее бескорневых энергетических аномалий практические возможности, касающиеся как прогноза и даже поисков неизвестных месторождений углеводородов, так и негативных последствий активной индустриальной нагрузки на природную среду? Предположительно, да.

\section{Литература}

1. Горяинов П.М. Тектоно-кессонный эффект в массивах горных пород и рудных месторождений-важное явление геодинамики / (П.М. Горяинов, И.В. Давиденко // ДАН СССР. 1979. Т. 247. № 5. С.1212-1215.

2. Горяинов П.М. О геодинамически необычных явлениях осадочного породо- и рудообразования в связи с проявлением тектоно-кессонного эффекта / П.М. Горяинов // Лит. и полезные ископаемые. 1983. № 5. C. 47-60.

3. Воробьев А.А. Высокие геоэлектрические поля. Томск. Изд. ТГУ. 1970.

4. Воробьев А.А. Тектоноэлектрические, тектономагнитные явления и их практическое приложение. Кн. в 5-ти частях. Ч. IV. Геоэлектрика и электрогеология / Воробьев А.А. // Томск. 1980. Деп. ВИНИТИ. 250 с.

5. Вовк И.Ф. Радиолиз подземных вод и его геохимическая роль. М. Недра. 1979. 231 с.

6. Вовк И.Ф. Радиолиз подземных вод как механизм геохимического превращения энергии радиоактивного распада в осадочных породах // Литология и полезные ископаемые. М.: Наука. № 4. 1981. С. 34 -43.

7. О роли химического действия ионизирующих излучений в геологических процессах углефикации органического вещества / Г.Г. Пименов, В.М. Бяков, О.П. Степанова. М.: ИТЭФ, 1982. 48 с.

8. Летников Ф.А. Синергетика геологических систем. Новосибирск. Наука. 1992. 230 с.

9. Тыминский В.Г. Геохимические предвестники землетрясений // Природа. № 2. С. 46-47.

10. Ферштатер Г.Б., Краснобаев А.А. Обдукционный магматизм и сопряженная мигматизация (на примере Урала) // Литосфера. 2007. № 3. Р. 66-85.

11. Харт Э. Гидратированный электрон / Харт Э., Анбар. Пер. с англ. В.И. Быковой, С.А. Кабакчи. Под ред. д-ра хим. наук, проф. А.К. Пикаева. Москва : Атомиздат. 1973. 280 с.

12. Areshev E.G., Tran Le Dong, Ngo Thuong San, Shnip O. A. Reservoirs in fractured basement on the continental shelf of Southern Vietnam // Journal of Petroleum Geology. 1992. V. 15. P. 451-464. doi: 10.1111/j.17475457.1992.tb01045.x

13. Ballhaus C., Wirth R., Fonseca R.O.C., Blanchard H., Pröll W., Bragagni A., Nagel T., Schreiber A., Dittrich S., Thome V., Hezel D.C., Below R., Cieszynski H. Ultra-high pressure and ultra-reduced minerals in ophiolites may form by lightning strikes // Geochemical Perspectives Letters. 2017. V. 5. P. 42-46. 